\title{
STRUCTURE, THERMAL AND ELECTRICAL PROPERTIES OF Fe-B-Co-Nb-Ni-Si HIGH-ENTROPY METALLIC GLASS
}

\author{
O.I. Kushnerov, V.F. Bashev \\ Oles Honchar Dnipro National University, Dnipro, Ukraine \\ e-mail:kushnrv@gmail.com
}

\begin{abstract}
New nanostructured $\mathrm{Fe}_{25} \mathrm{~B}_{17.5} \mathrm{Co}_{21.35} \mathrm{Nb}_{3.65} \mathrm{Ni}_{25} \mathrm{Si}_{7.5}$ high-entropy metallic glass is synthesized by dint of splat-quenching technique. The estimated cooling rate is $\sim 10^{6} \mathrm{~K} / \mathrm{s}$. The coherently scattering domain size (crystallite size) of films of $\mathrm{Fe}_{25} \mathrm{~B}_{17.5} \mathrm{Co}_{21.35} \mathrm{Nb}_{3.65} \mathrm{Ni}_{25} \mathrm{Si}_{7.5}$ high-entropy metallic glass estimated by the Sherer formula is $\sim 3 \mathrm{~nm}$. The high-entropy metallic glass shows a high temperature of glass transition $T_{g} \sim 800 \mathrm{~K}$ and the initial temperature of crystallization $T_{x} \sim 863 \mathrm{~K}$. After annealing to $\sim 1010 \mathrm{~K}$ (above the crystallization temperature) and subsequent slow cooling, the amorphous films crystallize with the formation of several crystalline phases. The temperature dependencies of electrical resistivity of the $\mathrm{Fe}_{25} \mathrm{~B}_{17.5} \mathrm{Co}_{21.35} \mathrm{Nb}_{3.65} \mathrm{Ni}_{25} \mathrm{Si}_{7.5}$ films indicate the occurrence of phase transformations. The phase transformation temperature (temperature of crystallization) is $\sim 869 \mathrm{~K}$. This value agrees well with the value obtained from the differential thermal analysis.

Keywords: high-entropy alloy, metallic glass, structure, phase composition, splat-quenching, differential thermal analysis.
\end{abstract}

Received 15.06.2020; Received in revised form 20.08.2020; Accepted 04.09.2020

\section{Introduction}

Over the past decade, a new class of materials called multi-principal element alloys (MPEA's) or high-entropy alloys (HEA's) or complex concentrated alloys (CCA's) has received significant research attention. Such alloys usually contain from 5 to 13 elements in equiatomic or close to equiatomic concentrations [1]. The correct choice of the number of components and their concentrations makes it possible to obtain an alloy with a high mixing entropy, the value of which is preserved both in the melt and after solidification. Simple solid solutions of substitution with face-centered or body-centered cubic crystal lattices are usually formed during the crystallization of such multicomponent alloys because of their high mixing entropy. On the other hand, it is possible to obtain the HEA's with a structure in which intermetallic compounds with high hardness values (Laves phases, $\sigma$ phase) will be combined with a simple solid solution characterized by high ductility [1]. Many high-entropy alloys possess unique properties, such as wear-resistance, resistance to corrosion and oxidation, radiation resistance, high hardness and strength [1-5]. It should also be noted the superior biocompatibility demonstrated by some HEA's [4]. So, the HE alloys may find use as materials for nuclear reactors applications, medicine, electronics devices, mechanical equipment, rocket casings, and engines, etc.

In contrast to HEA's, another type of modern material, the so-called metallic glass (MG) contains only one, occasionally two principal elements. The HEA's and MG's were explored separately until the amorphous high-entropy alloys have been successfully synthesized [1]. Such alloys were called high entropy metallic glasses (HE-MG's). The development of HEMG alloys was the basis for new methods of development and manufacturing of MG's. The HE-MG's (as happens with substances that simultaneously belong to different types of materials $[6,7])$ have excellent physical and mechanical properties combining the advantages of both metallic glasses and high-entropy alloys. So, HE-MG's exhibit considerable potential for various technical applications [8]. In particular, MG's usually are excellent soft magnetic materials. They have high saturation magnetization, low coercivity and power loss. Till now, serials of HE-MG systems have been synthesized [1, 8-12].

This study is devoted to developing a new nanostructured metallic glass of Fe-B-Co-NbNi-Si high-entropy alloy system with good thermal stability. 


\section{Materials and methods}

The as-cast sample of Fe-B-Co-Nb-Ni-Si alloy with a nominal composition of $\mathrm{Fe}_{25} \mathrm{~B}_{17.5} \mathrm{Co}_{21.35} \mathrm{Nb}_{3.65} \mathrm{Ni}_{25} \mathrm{Si}_{7.5}$ (in at. \%) was prepared with a Tamman high-temperature electric furnace in the argon gas flow using a copper mold. The mass losses during ingot preparation did not exceed $1 \%$ and the average rate of cooling was $\sim 10^{2} \mathrm{~K} / \mathrm{s}$. The as-cast ingot was thereafter remelted, and the nanostructured films were obtained from the melt by splat-quenching (SQ) technique. A technique for splat quenching used in the present work consisted of rapid cooling of melt drops upon their collision with the internal surface of a rapidly rotating hollow cylinder of copper. The cooling rate was estimated following the methodology proposed in [2]. We used the expression (1)

$$
V=\frac{\alpha \vartheta}{c \rho \delta},
$$

where $c$ is the heat capacity of film, $\rho$ is the film density, $\alpha$ is the coefficient of heat transfer, $\vartheta$ is the excess temperature of the film and $\delta$ is the film thickness [3]. Considering the thickness of fabricated splat-quenched films, the estimated rate of cooling was $\sim 10^{6} \mathrm{~K} / \mathrm{s}$. The X-ray diffraction analysis (XRD) was carried out using a DRON-2.0 diffractometer with monochromatized $\mathrm{Cu} K \alpha$ radiation. The diffraction patterns were processed using QualX2 software [13]. The temperature dependencies of electrical resistivity of the film were measured by the four-point technique upon continuously heating and subsequently cooling in the high vacuum with a pressure of $4 \cdot 10^{-2} \mathrm{~Pa}$. The heating rate from room temperature to $\sim 1010 \mathrm{~K}$ was $0.2 \mathrm{~K} / \mathrm{s}$. Annealed films were used for structural studies by X-ray diffraction analysis (with a photographic registration, in a Debye camera on the URS-2.0 diffractometer in filtered $\mathrm{CoK}_{\alpha}$ radiation). Debyegrams were digitally microphotometered and processed using a qualitative phase analysis software QualX2. The thermal behavior of the nanostructured films was studied by a differential thermal analysis technique (DTA) at a heating rate of $0.2 \mathrm{~K} / \mathrm{s}$.

\section{Results and discussion}

There are two main criteria by which the high-entropy alloys are usually characterized. This is the entropy of mixing $\Delta S_{\text {mix }}$ and the enthalpy of mixing $\Delta H_{\text {mix }}$. However, to predict the phase composition of HEA's, some additional parameters were proposed [1,2]. These parameters include, in particular, the valence electron concentration (VEC), the thermodynamic parameter $\Omega$, which takes into account the melting temperature, mixing entropy, and the mixing enthalpy. The important parameter is an atomic-size difference between alloy components, which is denoted as $\delta$.

Using the data from $[14,15]$, we calculated $\Delta S_{\text {mix }}, \Delta H_{m i x}, \delta$, VEC, $\Omega$, and $\gamma$ of the $\mathrm{Fe}_{25} \mathrm{~B}_{17.5} \mathrm{Co}_{21.35} \mathrm{Nb}_{3.65} \mathrm{Ni}_{25} \mathrm{Si}_{7.5} \mathrm{HEA}$ (Table 1).

Table 1

Electronic, thermodynamic, and the atomic-size parameters of the $\mathrm{Fe}_{25} \mathrm{~B}_{17.5} \mathrm{Co}_{21.35} \mathrm{Nb}_{3.65} \mathrm{Ni}_{25} \mathrm{Si}_{7.5} \mathrm{HEA}$

\begin{tabular}{|c|c|c|c|c|c|}
\hline$\Delta S_{\text {mix }}, \mathrm{J} /(\mathrm{mol} \cdot \mathrm{K})$ & $\Delta H_{\text {mix }}, \mathrm{kJ} / \mathrm{mol}$ & $\Omega$ & VEC & $\delta$ & $\gamma$ \\
\hline 13.653 & -26.295 & 0.987 & 7.439 & 14.41 & 1.545 \\
\hline
\end{tabular}

According to [16], high-entropy metallic glasses may form when $\Delta S_{m i x}, \Delta H_{m i x}$, and $\delta$ simultaneously satisfy the following conditions: $7 \leq \Delta S_{m i x} \leq 16 \mathrm{~J} /(\mathrm{mol} \cdot \mathrm{K})$, $-49 \leq \Delta H_{m i x} \leq-5.5 \mathrm{~kJ} / \mathrm{mol}$ and $\delta \geq 9$. Another condition indicating the possibility of metallic glass or intermetallic compounds forming is the value of the parameter $\Omega \leq 1.1$. As we can see from Table1, the $\mathrm{Fe}_{25} \mathrm{~B}_{17.5} \mathrm{Co}_{21.35} \mathrm{Nb}_{3.65} \mathrm{Ni}_{25} \mathrm{Si}_{7.5}$ alloy fully satisfies with all 
the mentioned above conditions, so $\Delta S_{\text {mix }}, \Delta H_{\text {mix }}, \delta, \Omega$, and $\gamma$ are the appropriate parameters for forecasting the phase composition of high-entropy alloys.

As is pointed in [9], the atomic-size difference $\delta$ is one of the most important parameters that determine the formation of a solid solution or amorphous phase in HEA. The value of $\delta$ should be large enough to provide sufficient stress at the atomic level, which is necessary for the destabilization of the solid solution phase [9]. Furthermore, to limit the long-range atomic diffusion and increase the efficiency of local packing, the negative value of $\Delta H_{m i x}$ and large $\delta$ are also necessary. So, the fulfillment of these conditions leads to high glass-forming ability and ensures the suppression of the crystalline phase formation during the cooling process [9].

The parameters of the crystal lattice and the phase composition of the investigated alloy (Table 2) were determined from X-ray diffraction patterns (Fig. 1, 2).

The phase composition of $\mathrm{Fe}_{25} \mathrm{~B}_{17.5} \mathrm{Co}_{21.35} \mathrm{Nb}_{3.65} \mathrm{Ni}_{25} \mathrm{Si}_{7.5} \mathrm{HEA}$

\begin{tabular}{|c|c|}
\hline Alloy & Phase composition \\
\hline As-cast $\mathrm{Fe}_{25} \mathrm{~B}_{17.5} \mathrm{Co}_{21.35} \mathrm{Nb}_{3.65} \mathrm{Ni}_{25} \mathrm{Si} 7.5$ & $\mathrm{FCC}(a=0.3574 \mathrm{~nm})+\mathrm{Fe}_{2} \mathrm{~B}$ \\
\hline $\begin{array}{ll}\text { Splat-quenched } & \text { film } \\
\mathrm{Fe}_{25} \mathrm{~B}_{17.5} \mathrm{Co}_{21.35} \mathrm{Nb}_{3.65} \mathrm{Ni}_{25} \mathrm{Si}_{7.5} & \\
\end{array}$ & fully glassy phase \\
\hline Annealed film $\mathrm{Fe}_{25} \mathrm{~B}_{17.5} \mathrm{Co}_{21.35} \mathrm{Nb}_{3.65} \mathrm{Ni}_{25} \mathrm{Si}_{7.5}$ & $\begin{array}{l}\mathrm{FCC}(a=0.3527 \mathrm{~nm})+(\mathrm{Co}, \mathrm{Ni}, \mathrm{Fe})_{2} \mathrm{~B}+\mathrm{Fe}_{x} \mathrm{Ni}_{23-\mathrm{x}} \mathrm{B}_{6}+\mathrm{Fe}_{3} \mathrm{Si} \\
+\mathrm{Co}_{2} \mathrm{Nb}\end{array}$ \\
\hline
\end{tabular}

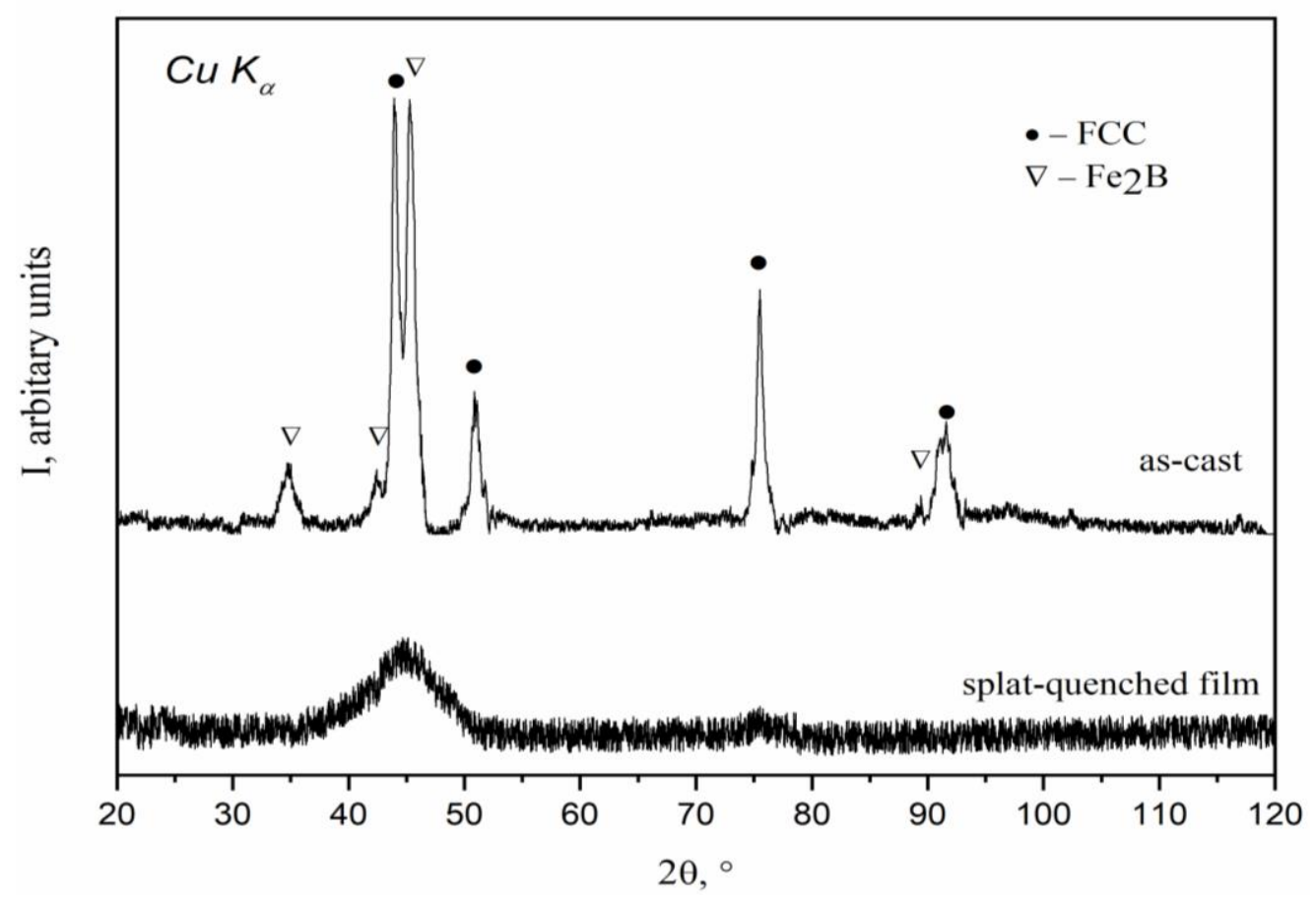

Fig. 1. XRD patterns of as-cast ingot and splat-quenched nanostructured film of $\mathrm{Fe}_{25} \mathrm{~B}_{17.5} \mathrm{Co}_{21.35} \mathrm{Nb}_{3.65} \mathrm{Ni}_{25} \mathrm{Si}_{7.5} \mathrm{HEA}$.

For the as-cast sample of $\mathrm{Fe}_{25} \mathrm{~B}_{17.5} \mathrm{Co}_{21.35} \mathrm{Nb}_{3.65} \mathrm{Ni}_{25} \mathrm{Si}_{7.5} \mathrm{HEA}$, the structure consists of a simple face-centered cubic phase and $\mathrm{Fe}_{2} \mathrm{~B}$ phase. The lattice parameters of the facecentered cubic phase suggest that it is formed based on $\gamma$-iron. (in [2] the lattice parameter $a$ of $\gamma$-iron was extrapolated at room temperature as $0.3572 \mathrm{~nm}$ ). 


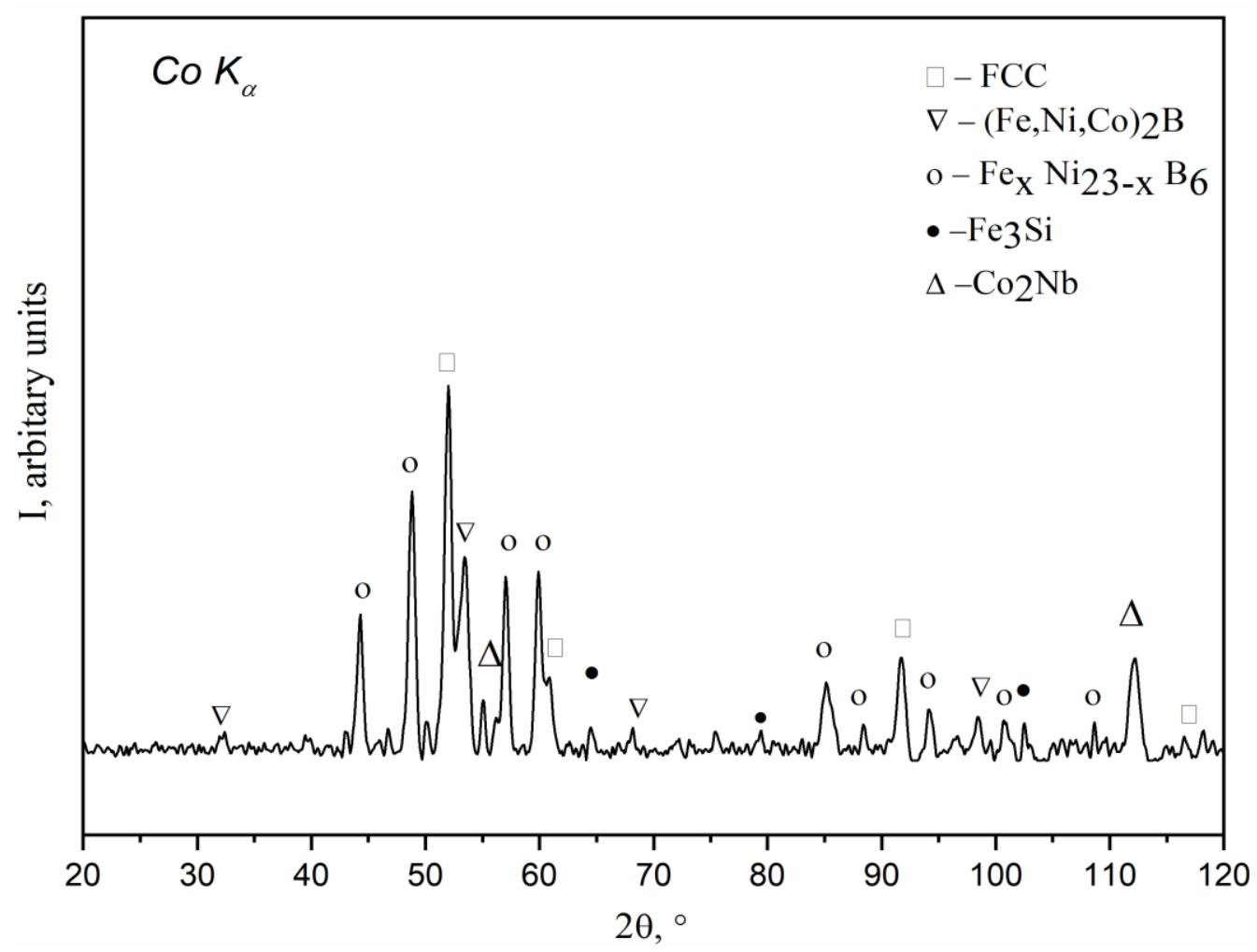

Fig. 2. XRD patterns of annealed nanostructured $\mathrm{Fe}_{25} \mathrm{~B}_{17.5} \mathrm{Co}_{21.35} \mathrm{Nb}_{3.65} \mathrm{Ni}_{25} \mathrm{Si}_{7.5} \mathrm{HE}-\mathrm{MG}$ film.

For the splat quenched $\mathrm{Fe}_{25} \mathrm{~B}_{17.5} \mathrm{Co}_{21.35} \mathrm{Nb}_{3.65} \mathrm{Ni}_{25} \mathrm{Si}_{7.5}$ alloy films the XRD pattern does not contain any clear crystalline peaks, only a broad maximum. This is a sign of a completely glassy structure. A coherently scattering domain size (crystallite size) of HEMG estimated by the Sherer formula was $\sim 3 \mathrm{~nm}$. After annealing to $\sim 1010 \mathrm{~K}$ (above the crystallization temperature) and subsequent slow cooling, the films crystallize with the formation of several crystalline phases (Table 2). The much more complex phase composition that is observed in annealed films compared to as-cast samples, is obviously explained by their low cooling rate. As a result, a substantially more equilibrium multiphase state is formed in the annealed films.

Fig. 3 shows the DTA curve of the nanostructured $\mathrm{Fe}_{25} \mathrm{~B}_{17.5} \mathrm{Co}_{21.35} \mathrm{Nb}_{3.65} \mathrm{Ni}_{25} \mathrm{Si}_{7.5} \mathrm{HE}-$ MG film. The curve contains an obvious glass transition stage, with a supercooled liquid region after it and then an exothermic peak, indicating the crystallization. This behavior indicates the glassy nature of the sample. The temperature of glass transition $T_{g}$ and the initial temperature of crystallization $T_{x}$ are marked by arrows and equal to $800 \mathrm{~K}$ and 863 $\mathrm{K}$, respectively. Considering that only one exothermic peak is visible on the DTA curve, crystallization occurs through one stage.

Let us consider the dependence of the relative electrical resistivity of nanostructured films $R(T) / R_{0}(300 \mathrm{~K})$. The beginning of the irreversible decrease of resistivity during heating indicates the occurrence of some phase transformations in the film. As can be seen from Fig. 4, phase transformation temperature (temperature of crystallization) in $\mathrm{Fe}_{25} \mathrm{~B}_{17.5} \mathrm{Co}_{21.35} \mathrm{Nb}_{3.65} \mathrm{Ni}_{25} \mathrm{Si}_{7.5} \mathrm{HE}-\mathrm{MG}$ film is $\sim 869 \mathrm{~K}$. This value agrees well with the value obtained from DTA. At the same time, the presence of bends on the curve in the phase transformation region indicates the formation of several crystalline phases. After completion of the crystallization process, the dependence of the resistance on temperature has the usual character where the resistance decreases with decreasing temperature. 


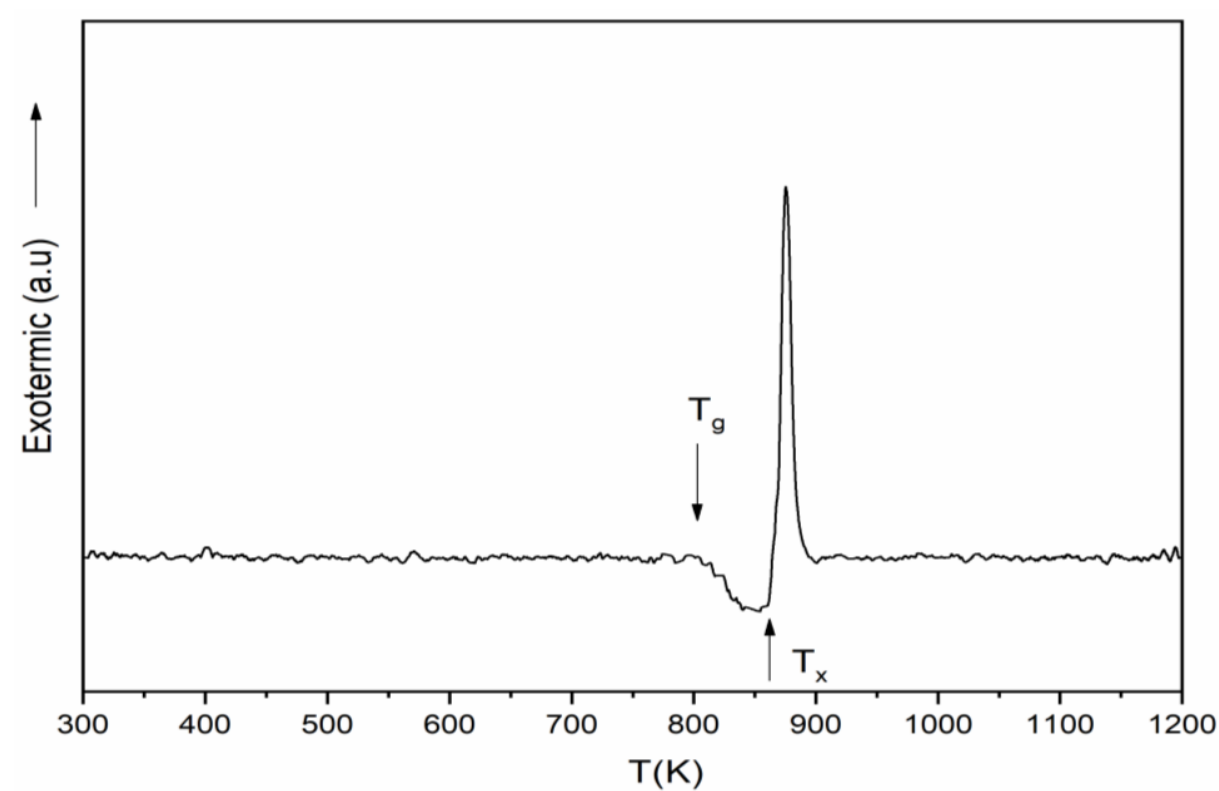

Fig. 3. DTA curve of the nanostructured $\mathrm{Fe}_{25} \mathrm{~B}_{17.5} \mathrm{Co}_{21.35} \mathrm{Nb}_{3.65} \mathrm{Ni}_{25} \mathrm{Si}$ 7.5 $\mathrm{HE}-\mathrm{MG}$ film.

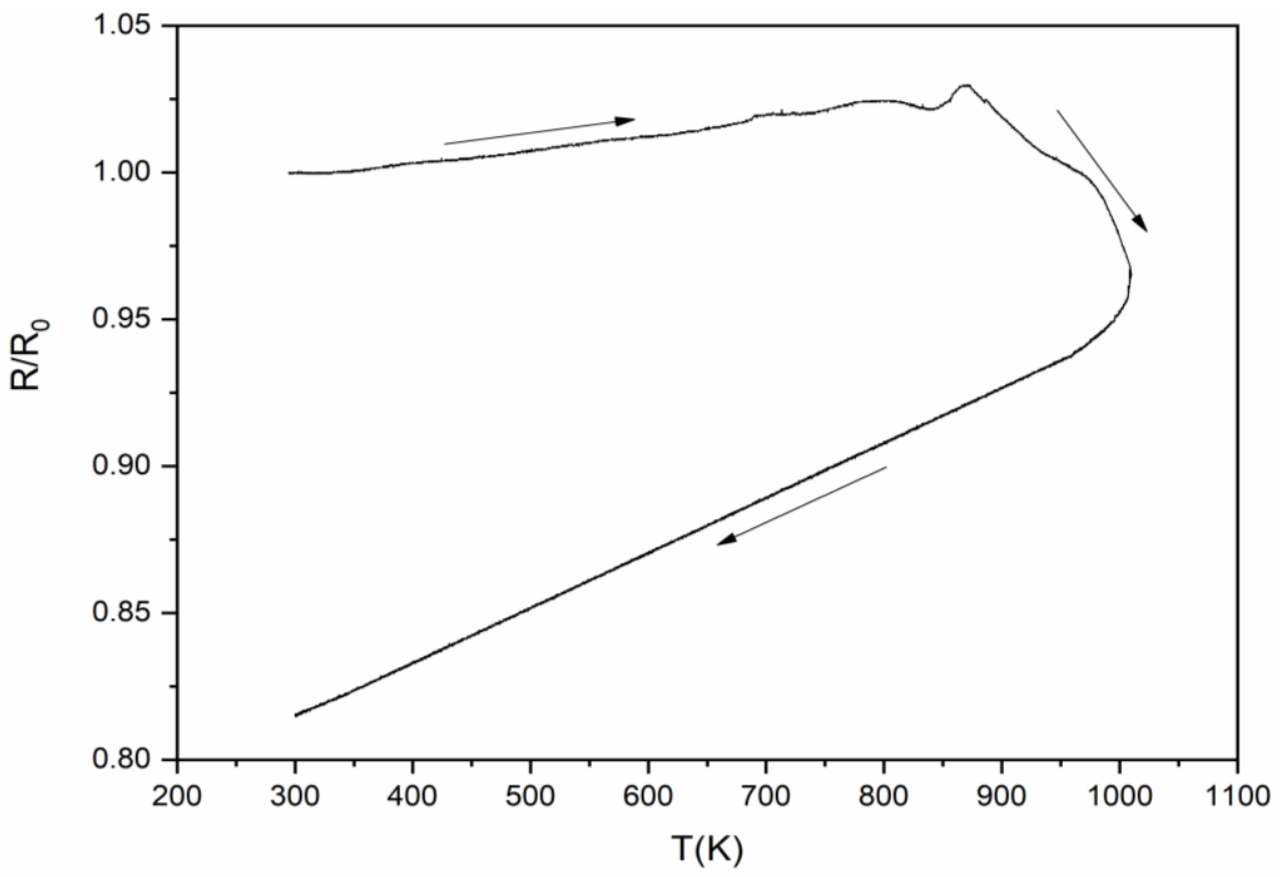

Fig. 4. The temperature dependencies of relative electrical resistivity of $\mathrm{Fe}_{25} \mathrm{~B}_{17.5} \mathrm{Co}_{21.35} \mathrm{Nb}_{3.65} \mathrm{Ni}_{25} \mathrm{Si}_{7.5} \mathrm{HE}-\mathrm{MG}$ film.

\section{Conclusions}

In this research, a new nanostructured $\mathrm{Fe}_{25} \mathrm{~B}_{17.5} \mathrm{Co}_{21.35} \mathrm{Nb}_{3.65} \mathrm{Ni}_{25} \mathrm{Si}$ 7.5 high-entropy metallic glass has been synthesized by dint of splat-quenching technique. The temperature of glass transition $T_{g}$ and the initial temperature of crystallization $T_{x}$ are equal to $800 \mathrm{~K}$ and $863 \mathrm{~K}$, respectively. The phase transformation temperature (temperature of crystallization) determined from the temperature dependencies of electrical resistivity was $\sim 869 \mathrm{~K}$. The obtained high-entropy metallic glass with high glass-forming ability and high thermal stability can be used for both engineering and functional purposes. 


\section{References}

1. Murty, B.S. High-entropy alloys. 2nd edition / B. S. Murty, J. W. Yeh, S. Ranganathan, P. P. Bhattacharjee. - Elsevier, 2019. - 363 p.

2. Bashev, V.F. Structure and properties of cast and splat-quenched high-entropy $\mathrm{Al}-\mathrm{Cu}-\mathrm{Fe}-\mathrm{Ni}-\mathrm{Si}$ alloys / V.F. Bashev, O.I. Kushnerov // Physics of Metals and Metallography. - 2017. - Vol. 118, No. 1. - P. $39-47$.

3. Miracle, D.B. A critical review of high entropy alloys and related concepts/ D.B. Miracle, O.N. Senkov // Acta Materialia. - 2017. - Vol. 122. - P. 448 - 511.

4. Wang, S. TiZrNbTaMo high-entropy alloy designed for orthopedic implants: ascast microstructure and mechanical properties / S. Wang, J. Xu // Materials Science and Engineering: C. $-2017 .-$ Vol. 73. - P. $80-89$.

5. Pogrebnjak, A.D. Irradiation resistance, microstructure and mechanical properties of nanostructured (TiZrHfVnBTa)N coatings / A.D. Pogrebnjak, I.V. Yakushchenko, O.V. Bondar, V.M. Beresnev, K. Oyoshi, O.M. Ivasishin, H. Amekura, Y. Takeda, M. Opielak, C. Kozak // Journal of Alloys and Compounds. - 2016. - Vol. 679. - P. $155-163$.

6. Dudnik, E.F. Higher order ferroic properties of TGS monocrystals / E.F. Dudnik, A.I. Kushnerev, V.M. Duda // Materials Research Innovations. - 1999. - Vol. 2, No. 5. - P. 309 -311.

7. Dudnik, E.F. Second-order ferroic properties of a $\mathrm{Pb}_{5} \mathrm{Ge}_{3} \mathrm{O}_{11}$ uniaxial ferroelectric / E.F. Dudnik, V.M. Duda, A.I. Kushnerov // Physics of the Solid State. 2001. - Vol. 43, No. 12. - P. 2280 - 2283.

8. Qi, T. Soft magnetic $\mathrm{Fe}_{25} \mathrm{Co}_{25} \mathrm{Ni}_{25}(\mathrm{~B}, \mathrm{Si})_{25}$ high entropy bulk metallic glasses/ T. Qi, Y. Li, A. Takeuchi, G. Xie, H. Miao // Intermetallics. - 2015. - Vol. 66. - P. 8 - 12.

9. Li, Y. New soft magnetic $\mathrm{Fe}_{25} \mathrm{Co}_{25} \mathrm{Ni}_{25}(\mathrm{P}, \mathrm{C}, \mathrm{B})_{25}$ high entropy bulk metallic glasses with large supercooled liquid region / Y. Li, W. Zhang, T. Qi // Journal of Alloys and Compounds. - 2017. - Vol. 693. - P. $25-31$.

10. Xu, Y. Formation and properties of $\mathrm{Fe}_{25} \mathrm{Co}_{25} \mathrm{Ni}_{25}(\mathrm{P}, \mathrm{C}, \mathrm{B}, \mathrm{Si})_{25}$ high-entropy bulk metallic glasses / Y. Xu, Y. Li, Z. Zhu, W. Zhang // Journal of Non-Crystalline Solids. 2018. - Vol. 487. - P. $60-64$.

11. Wei, R. Soft magnetic $\mathrm{Fe}_{26.7} \mathrm{Co}_{26.7} \mathrm{Ni}_{26.6} \mathrm{Si}_{9} \mathrm{~B}_{11}$ high entropy metallic glass with good bending ductility / R. Wei, J. Tao, H. Sun, C. Chen, G.W. Sun, F.S. Li // Materials Letters. - 2017. - Vol. 197. - P. 87 - 89.

12. Ding, J. High entropy effect on structure and properties of ( $\mathrm{Fe}, \mathrm{Co}, \mathrm{Ni}, \mathrm{Cr})-\mathrm{B}$ amorphous alloys/ J. Ding, A. Inoue, Y. Han, F. L. Kong, S. L. Zhu, Z. Wang, E. Shalaan, F. Al-Marzouki // Journal of Alloys and Compounds. - 2017. - Vol. 696. - P. $345-352$.

13. Altomare, A. Main features of Qualx2.0 software for qualitative phase analysis / A. Altomare, N. Corriero, C. Cuocci, A. Falcicchio, A. Moliterni, R. Rizzi // Powder Diffraction. - 2017. - Vol. 32, No. S1. - P. S129 - S134.

14. Takeuchi, A. Classification of bulk metallic glasses by atomic size difference, heat of mixing and period of constituent elements and its application to characterization of the main alloying element / A. Takeuchi, A. Inoue // Materials Transactions. - 2005. Vol. 46. -P. $2817-2829$.

15. Troparevsky, M.C. Criteria for predicting the formation of single-phase highentropy alloys / M.C. Troparevsky, J.R. Morris, P.R.C. Kent, A.R. Lupini, G.M. Stocks // Physical Review X. - 2015. - Vol. 5, No. 1. - P. 0110141-1-011014-6.

16. Guo, S. Phase stability in high entropy alloys: Formation of solid-solution phase or amorphous phase / S. Guo, C.T. Liu // Progress in Natural Science: Materials International. - 2011. -Vol. 21, Iss. 6. - P. 433 - 446. 